\title{
Effect of royal jelly ingestion for six months on healthy volunteers
}

\author{
Hiroyuki Morita*, Takahide Ikeda, Kazuo Kajita, Kei Fujioka, Ichiro Mori, Hideyuki Okada, Yoshihiro Uno \\ and Tatsuo Ishizuka
}

\begin{abstract}
Background: Royal jelly is a widely ingested supplement for health, but its effects on humans are not well known. The objective was to evaluate the effects of long-term royal jelly ingestion on humans.

Methods: We conducted a randomized placebo-controlled, double-blind trial. A total of 61 healthy volunteers aged 42-83 years were enrolled and were randomly divided into a royal jelly group $(n=31)$ and a control group $(n=30)$.

Three thousand $\mathrm{mg}$ of royal jelly (RJ) or a placebo in $100 \mathrm{ml}$ liquid/day were ingested for 6 months. The primary outcomes were changes in anthropometric measurements and biochemical indexes from baseline to 6 months after intervention.
\end{abstract}

Results: Thirty subjects in the RJ group and 26 in the control group were included in the analysis of endpoints. In an adjusted mean change of the variables from the baseline, significant differences between the two groups could be found in red blood cell counts $\left(+0.16 \times 10^{6} / \mu \mathrm{L}\right.$ for the RJ group vs. $-0.01 \times 10^{6} / \mu \mathrm{L}$ for the control group,

$P=0.0134)$, hematocrit ( $+0.9 \%$ vs. $-0.8 \%, P=0.0251)$, log (fasting plasma glucose) $(+0.01 \pm 0.01 \mathrm{log} \mathrm{mg} / \mathrm{dL}$ vs. $+0.05 \pm 0.01 \mathrm{log} \mathrm{mg} / \mathrm{dL}, P=0.0297$ ), $\log$ (insulinogenic index) (+0.25 vs. $-0.13, P=0.0319), \log$ dehydroepiandrosterone sulfate (DHEA-S) $(+0.08 \mathrm{log} \mu \mathrm{g} / \mathrm{dL}$ vs. $+0.20 \mathrm{log} \mu \mathrm{g} / \mathrm{dL}, \mathrm{P}=0.0483)$, log testosterone (T) $(+0.12 \pm 0.04 \mathrm{log} \mathrm{ng} / \mathrm{mL}$ vs. $-0.02 \pm 0.05 \mathrm{log} \mathrm{ng} / \mathrm{mL}, P=0.0416)$, log T/DHEA-S ratio $(+0.05 \pm 0.05$ vs. $-0.23 \pm 0.59$, $P=0.0015)$, and in one of the SF-36 subscale scores, mental health $(M H)(+4$ vs. $-7, P=0.0276)$.

Conclusions: Six-month ingestion of RJ in humans improved erythropoiesis, glucose tolerance and mental health. Acceleration of conversion from DHEA-S to T by RJ may have been observed among these favorable effects.

Keywords: Testosterone, Dehydroepiandrosterone sulfate, Erythropoiesis, Glucose tolerance, SF-36

\section{Introduction}

Royal jelly (RJ) is mainly secreted by the hypopharyngeal and mandibular glands of worker honeybees (Apis mellifera) between the sixth and twelfth days of their life [1] and is an essential food for the development of the queen honeybee. $\mathrm{RJ}$ is a complex substance containing a unique combination of proteins (12-15\%), sugars (10-12\%), lipids (3-7\%), amino acids, vitamins, and minerals [2]. Compared with the short-lived and infertile worker bees, the queen bee, which is exclusively fed RJ, is characterized by her extended lifespan and her well-developed gonads. Therefore, RJ has been long- used as a supplement for nutrition, anti-aging or infertility.

\footnotetext{
* Correspondence: hmorita@gifu-u.ac.jp

Department of General Internal Medicine, Gifu University Graduate School of Medicine, Gifu 501-1194, Japan
}

RJ has been demonstrated to possess many pharmacological activities in experimental animals, including antitumor [3], anti-oxidant [4], anti-inflammatory [5], antibacterial [6], anti-allergic [7], anti-aging [8] and antihypertensive properties [9]. In humans, its oral ingestion improves lipoprotein metabolism and reduces serum total cholesterol (TC) and low-density lipoprotein (LDL) levels [10]. Lady 4, a combination of four natural components including RJ, promoted health and well-being in postmenopausal women [11].

RJ develops the queen bee gonads. An RJ diet induced higher testosterone (T) content and more intensive spermatogenesis in hamster testis [12] and increased serum testosterone levels in heat stressed male rabbits [13]. It may also modulate sex hormones in humans. Dehydroepiandrosterone sulfate (DHEA-S), 
which declines during normal aging, may serve as a potential longevity marker $[14,15]$ and may improve insulin resistance [16-18]. Men with higher serum DHEA-S had a longer life span in a Baltimore longitudinal study of aging male humans [19]. Estradiol (E2) is more important than testosterone in the pathway to insulin resistance in healthy, young postmenopausal women [20].

We conducted a randomized placebo-controlled, double-blind trial to evaluate how RJ affects biochemical, nutritional and glucose tolerance.

\section{Subjects and methods Subjects}

All subjects were healthy volunteers recruited mainly among adults living in Takayama City in Japan in May 2008. They were users of a home health care telemedicine system managed by ISET Co. (Tsu, Japan). The purpose, benefit and risk of this study were explained to each subject and a written informed consent was obtained from all the subjects. Their lifestyle habits, past history, present illness and medicines were obtained by a written questionnaire at the enrollment. Diabetic patients with poor blood sugar control (HbA1c > = 7.4\%) were excluded. A subject who had undertaken a gastrectomy was also excluded.
Sixty-one healthy volunteers aged 42-83 years were enrolled in the present study (Figure 1). The subjects were randomly divided into two groups: one was a RJ group $(n=31)$ and the other was a control group $(\mathrm{n}=30)$. Randomization was performed by random numbers generated by a computer at ISET Co. The RJ group took $100 \mathrm{ml}$ liquid containing $3000 \mathrm{mg}$ of RJ a day for six months and the control group received the same volume and appearance of liquid without containing RJ as a placebo for the same period. The same amount of ingredients, such as fructose, citrate, vitamin B2 and several flavors, were contained in both kinds of liquid. These liquids were prepared by API Co., Ltd. (Gifu, Japan) and were provided to all the participants. The trial was approved by the Ethics Committee of Gifu University Graduate School of Medicine (No. 20-34).

\section{Methods}

Anthropometric measurements, blood and urinary examinations were assessed at a checkup which we held before and after intervention for six months. Height, weight, body mass index (BMI), systolic and diastolic blood pressures, pulse rate and waist circumference were measured as anthropometry. Brachial-ankle pulse wave velocity (baPWV) and bone mineral density (BMD) at the calcaneus were determined using a pulse pressure

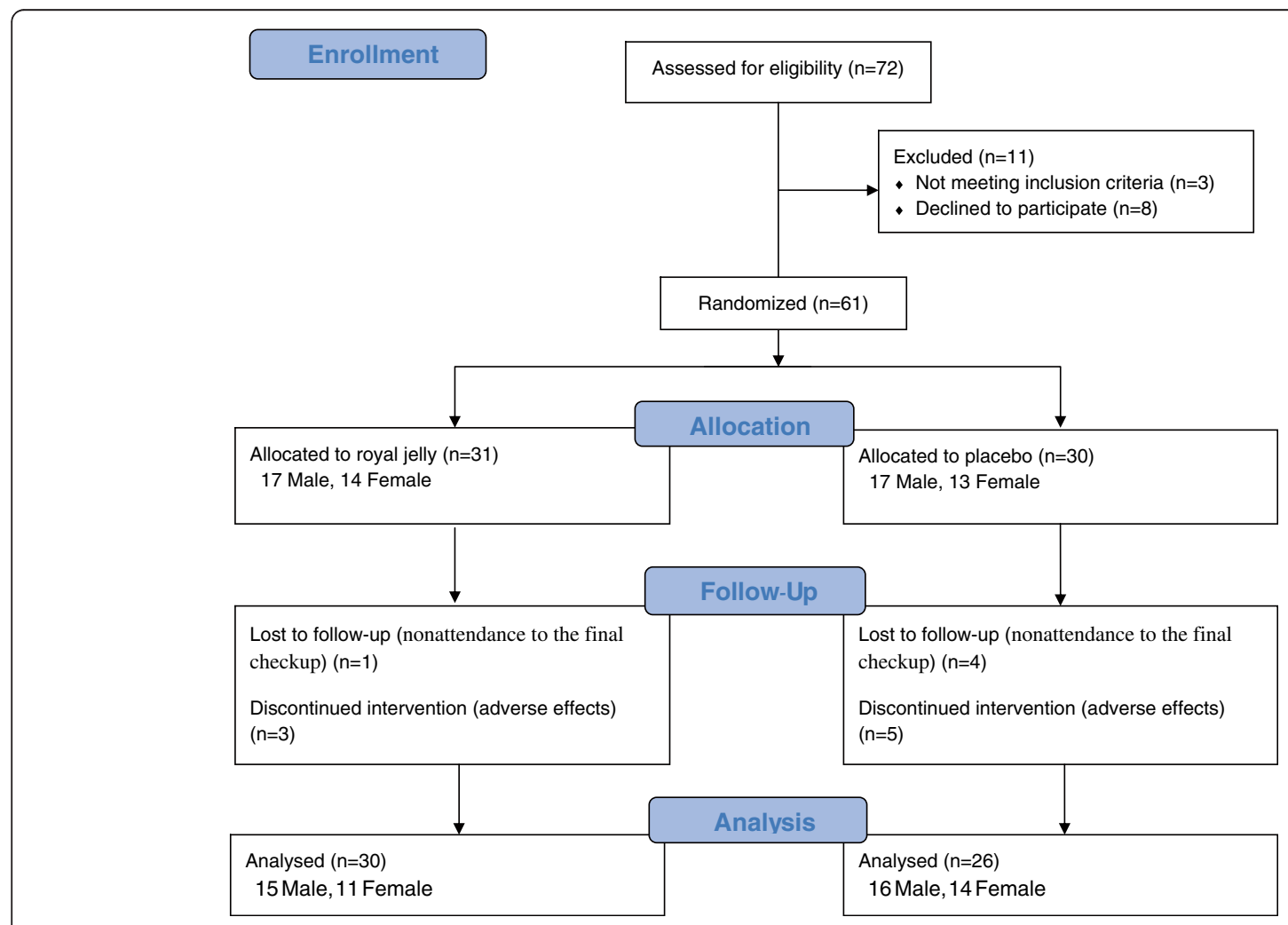

Figure 1 Flow of participants through the present study. 
analyzer (Form PWV/ABI; Nihon Colin Co., Tokyo, Japan) and an ultrasound bone densitometer (CM-200; Erk Co., Tokyo, Japan), respectively. Blood pressure, BMD and baPWV were measured twice and the mean values were adopted.

All blood samples were drawn between 0700 and $0800 \mathrm{~h}$ a.m. after an overnight fast. A 75-g oral glucose tolerance test (OGTT) for measuring glucose and insulin drawn before and at 30 and 120 min after oral glucose ingestion was performed. Additional assessments included as follows: screening blood tests, HbA1c, plasma homocystein and 3-methoxy-4-hydroxy-phenylglycol (MHPG), serum cystatin $\mathrm{C}$, high sensitive C-reactive protein (hsCRP), leptin, high-molecular-weight adiponectin (hmw-adiponectin), prolactin, E2, T, DHEA-S, undercarboxylated osteocalcin (ucOC), N-telopeptides of type I collagen (NTx) and ratio of urinary 8hydroxy-2'-deoxyguanosine (8-OHdG) to creatinine. Plasma and serum was obtained by centrifuging the blood at $1,000 \times \mathrm{g}$ for $15 \mathrm{~min}$ at $4 \mathrm{C}$ immediately after drawing blood. We commissioned SRL Inc. (Tachikawa, Japan) to measure all of the hematological variables, serum and urinary biochemical and hormonal concentrations. Homocystein and MHPG were measured by HPLC, cystatin $C$ by colloidal gold enhanced immunoassay, leptin, E2 and ucOC by RIA, hmw-adiponectin, prolactin, $\mathrm{T}$ and DHEA-S by CLEIA, and hsCRP, NTx and 8-OHdG by ELISA.

The homeostatic model assessment-insulin resistance index (HOMA-IR), which is calculated as fasting immunoreactive insulin (FIRI) $(\mu \mathrm{U} / \mathrm{mL}) \mathrm{x}$ fasting plasma glucose (FPG) $(\mathrm{mg} / \mathrm{dL})$ divided by 405 , was used to assess insulin resistance. HOMA of $\beta$-cell function index (HOMA-B), computed as the product of $360 \times$ FIRI $(\mu \mathrm{U} /$ $\mathrm{mL}$ ) divided by the value of FPG $(\mathrm{mg} / \mathrm{dL})$ minus 63 , has been proposed to be a good measure of steady state $\beta$ cell function. Insulinogenic index (IGI), which is the ratio of the 30-min increment in insulin level to the 30-min increment in glucose level in the OGTT, was used as an index of early-phase insulin secretion from $\beta$-cells. Estimated glomerular filtration rate (eGFR) and non-high density lipoprotein cholesterol (non-HDL-C) were calculated as $194 \times$ age $^{-0.287} \mathrm{x}$ serum creatinine (CRE) ${ }^{-1.094}$ (x 0.739 if female) and TC - HDL-C, respectively.

General health status was assessed with the use of the Japanese version of the Medical Outcomes Study 36Item Short-Form Health Survey (SF-36v2 ${ }^{\mathrm{TM}}$ ) $[21,22]$ before and after intervention. The SF-36, a standardized and written questionnaire, evaluates eight dimensions of health: physical functioning (PF), role limitations due to physical problems (RP), bodily pain (BP), general health perception $(\mathrm{GH})$, vitality $(\mathrm{VT})$, social functioning (SF), role of limitation due to emotional problems (RE) and mental health $(\mathrm{MH})$. Scores for each domain range from
0 to 100. A higher score indicates better health status. The scores were calculated by a Japanese version of the scoring program. The SF-36v2 $2^{\mathrm{TM}}$ and the scoring program were obtained from the Institute for Health Outcomes \& Process Evaluation Research (Kyoto, Japan).

A target sample size of 58 participants (29 subjects per group) was estimated to provide $>=80 \%$ power at a $5 \%$ level of significance (2-sided) to detect a 0.9 difference in the change in hematocrit $(\mathrm{Ht})$ from baseline to the end of intervention period between the 2 groups, with an assumption of an SD of 5.0 and allowance for a 10\% loss to follow up.

\section{Statistical analysis}

Analyses were done according to intention to treat. Data were expressed as mean \pm SEM. Baseline characteristics were compared between the RJ group and the control group using the Fisher exact test for categorical variables and Student's $t$-test for continuous ones. Non-normally distributed variables were log transformed for further analysis if they were applicable. An analysis of covariance (ANCOVA), adjusted for age, sex, smoking and drinking habits, hypertension, diabetes mellitus, dyslipidemia, arrhythmia, history of ischemic heart disease and apoplexy and the baseline value as covariates, was used to compare change from baseline to 6 months after intervention in anthropometric and biochemical variables and the SF-36 subscale scores between the RJ and control groups. Regarding DHEA-S, T and E2, analyses by gender were also done because the normal range of these hormones was quite different between the sexes. $P$ values less than 0.05 were considered statistically significant. SAS 9.1.3 Service Pack 4 for Windows (SAS Institute Inc., Cary, NC) was used for all statistical analyses.

\section{Results}

Among the initially enrolled 61 volunteers, 3 in the RJ group and 5 subjects in the control group quit the ingestion during the intervention period (Figure 1). The reasons why they gave it up were abdominal fullness, diarrhea, and dislike of the taste but the symptoms were not severe and they recovered after discontinuance. There was no difference in the adverse effects between the control and RJ groups. Among the 7 subjects who gave up the ingestion, two in the RJ group and two in the control group underwent the final checkup and were not excluded from the present study according to intention to treat analysis. One subject in the control group who ingested the placebo completely for six months was excluded because of nonattendance to the final checkup. Finally, 30 in the RJ group and 26 subjects in the control group were analyzed. 
There were no significant differences in age, sex, smoking and drinking habits, hypertension, diabetes mellitus, dyslipidemia, arrhythmia, history of ischemic heart disease and stroke at baseline between the two groups (data not shown). Among the anthropometric and biochemical examinations, all variables were no different between the groups except for lower PF and $\mathrm{MH}$ of SF-36 subscales in the RJ group as shown in Table 1.

In the mean change of variables from the baseline adjusted for age, sex, smoking and drinking habits, hypertension, diabetes mellitus, dyslipidemia, arrhythmia, history of ischemic heart disease and apoplexy, peripheral red blood cell counts (RBC), Ht, log IGI, log T, log T/DHEA-S ratio and MH of SF-36 subscales were higher and $\log$ FPG, and log DHEA-S were lower in the RJ group than those in the control group (Table 2). According to analysis by gender, the change of log T/DHEA-S ratio in men was significantly higher in the RJ group but that of $\log$ E2/T in both sexes was no different between the groups. NTx, PF and MH were higher in men of the RJ group than in those in the control one (data not shown). Log TG and Ht were higher and log FPG was lower in women (data not shown).

There were no significant differences in BMI, waist circumference, lipids, hepatic and renal functions, atherosclerotic (blood pressure, baPWV, homocystein and hmw-adiponectin), other glycemic (log HbA1c, log HOMA-IR, log HOMA-B and log leptin), and bone metabolic variables (BMD, NTx, log ucOC) (data not shown).

\section{Discussion}

The honeybee forms two female castes: the queen and the worker. This dimorphism does not depend on genetic differences but on ingestion of RJ. Recently, it has been demonstrated that royalactin, a $57-\mathrm{kDa}$ protein, in RJ induces the differentiation of honeybee larvae into queens through an epidermal growth factor receptormediated signaling pathway, increasing body size and ovary development [23].

RJ has been widely used as a supplemental food for health promotions, but little effects on human beings have been objectively shown. Only three randomized controlled trials to investigate the effect of RJ on humans have been published in English so far. Improvement of lipid metabolism [10], quality of life in postmenopausal women [11] and fertility of couples affected by asthenozoospermia [24] have been reported.

The present trail has shown increases in $\mathrm{RBC}$ and $\mathrm{Ht}$ as well as improvement of glucose tolerance and mental health. However, no apparent effect on serum lipids as shown by Guo et al. [10] was observed. They have shown that serum TC and LDL-C in the RJ group decreased significantly more than those in the control group. One of
Table 1 Main baseline characteristics of the subjects in the $\mathrm{RJ}$ and control group

\begin{tabular}{|c|c|c|c|}
\hline & $\mathrm{RJ}$ & Control & $P$ value \\
\hline $\mathrm{BMI}\left(\mathrm{kg} / \mathrm{m}^{2}\right)$ & $22.7 \pm 0.5$ & $22.8 \pm 0.5$ & 0.9533 \\
\hline Waist circumference $(\mathrm{cm})$ & $86.3 \pm 1.3$ & $84.1 \pm 1.5$ & 0.2626 \\
\hline Systolic BP (mmHg) & $135 \pm 3$ & $137 \pm 4$ & 0.7135 \\
\hline Diastolic BP (mmHg) & $79 \pm 2$ & $80 \pm 2$ & 0.6125 \\
\hline WBC $(/ \mu \mathrm{L})$ & $5090 \pm 240$ & $5420 \pm 280$ & 0.3652 \\
\hline $\mathrm{RBC}\left(\times 10^{6} / \mu \mathrm{L}\right)$ & $4.52 \pm 0.08$ & $4.64 \pm 0.08$ & 0.3049 \\
\hline $\mathrm{Hb}(\mathrm{g} / \mathrm{dL})$ & $14,2 \pm 0.3$ & $14.5 \pm 0.3$ & 0.5076 \\
\hline $\mathrm{Ht}(\%)$ & $44.6 \pm 0.7$ & $46.0 \pm 0.9$ & 0.1915 \\
\hline $\operatorname{PLT}\left(x 10^{3} / \mu \mathrm{L}\right)$ & $193 \pm 11$ & $211 \pm 10$ & 0.2222 \\
\hline $\log$ TG (log mg/dL) & $4.79 \pm 0.13$ & $4.54 \pm 0.09$ & 0.1128 \\
\hline $\mathrm{HDL}-\mathrm{C}(\mathrm{mg} / \mathrm{dL})$ & $57 \pm 3$ & $59 \pm 3$ & 0.5709 \\
\hline $\mathrm{LDL}-\mathrm{C}(\mathrm{mg} / \mathrm{dL})$ & $110 \pm 5$ & $126 \pm 4$ & 0.0186 \\
\hline $\log$ FPG (log mg/dL) & $4.62 \pm 0.03$ & $4.63 \pm 0.02$ & 0.7231 \\
\hline $\log F I R I(\log \mu \mid U / m L)$ & $1.38 \pm 0.14$ & $1.66 \pm 0.11$ & 0.1375 \\
\hline $\log \mathrm{HbA1c}(\log \%)$ & $1.7 \pm 0.0$ & $1.7 \pm 0.0$ & 0.6786 \\
\hline $\log$ HOMA-IR & $-0.00 \pm 0.16$ & $0.29 \pm 0.11$ & 0.1399 \\
\hline $\log \mathrm{HOMA-B}$ & $3.66 \pm 0.13$ & $3.90 \pm 0.12$ & 0.2009 \\
\hline $\log |G|$ & $-0.54 \pm 0.18$ & $-0.41 \pm 0.20$ & 0.6309 \\
\hline $\log$ DHEA-S $(\log \mu \mathrm{g} / \mathrm{dL})$ & $4.22 \pm 0.10$ & $4.46 \pm 0.13$ & 0.1541 \\
\hline male & $4.52 \pm 0.11$ & $4.74 \pm 0.13$ & 0.2044 \\
\hline female & $3.88 \pm 0.20$ & $4.07 \pm 0.19$ & 0.4258 \\
\hline $\log T(\log n g / m L)$ & $-0.32 \pm 0.38$ & $0.01 \pm 0.41$ & 0.5544 \\
\hline male & $1.52 \pm 0.05$ & $1.68 \pm 0.08$ & 0.0926 \\
\hline female & $-2.41 \pm 0.25$ & $-2.27 \pm 0.25$ & 0.6829 \\
\hline $\log$ E2 (log pg/mL) & $2.41 \pm 0.14$ & $2.74 \pm 0.21$ & 0.1948 \\
\hline male & $3.11 \pm 0.08$ & $3.29 \pm 0.09$ & 0.1138 \\
\hline female & $1.61 \pm 0.00$ & $1.99 \pm 0.38$ & 0.3409 \\
\hline $\log$ T/DHEAS & $-6.84 \pm 0.32$ & $-6.74 \pm 0.34$ & 0.8436 \\
\hline male & $-5.30 \pm 0.11$ & $-5.35 \pm 0.16$ & 0.7915 \\
\hline female & $-8.59 \pm 0.20$ & $-8.64 \pm 0.13$ & 0.8389 \\
\hline $\log E 2 / T$ & $-4.18 \pm 0.26$ & $-4.18 \pm 0.30$ & 0.9994 \\
\hline male & $-5.32 \pm 0.08$ & $-5.30 \pm 0.08$ & 0.8960 \\
\hline female & $-2.88 \pm 0.25$ & $-2.65 \pm 0.31$ & 0.5678 \\
\hline \multicolumn{4}{|l|}{ SF-36 subscale scores } \\
\hline PF & $81 \pm 3$ & $89 \pm 2$ & $0.0393^{*}$ \\
\hline $\mathrm{RP}$ & $84 \pm 4$ & $88 \pm 4$ & 0.4342 \\
\hline $\mathrm{BP}$ & $66 \pm 5$ & $69 \pm 4$ & 0.5467 \\
\hline $\mathrm{GH}$ & $61 \pm 3$ & $63 \pm 3$ & 0.5936 \\
\hline VT & $61 \pm 3$ & $67 \pm 3$ & 0.1529 \\
\hline SF & $88 \pm 3$ & $94 \pm 2$ & 0.0922 \\
\hline RE & $91 \pm 3$ & $91 \pm 3$ & 0.9693 \\
\hline $\mathrm{MH}$ & $71 \pm 3$ & $80 \pm 3$ & $0.0289^{*}$ \\
\hline
\end{tabular}

Abbreviations were denoted in the text. ${ }^{*} P<0.05$. 
Table 2 Changes of main variables from baseline to 6 months after intervention

\begin{tabular}{|c|c|c|c|}
\hline & RJ & Control & $P$ value \\
\hline $\mathrm{BMI}\left(\mathrm{kg} / \mathrm{m}^{2}\right)$ & $+0.1 \pm 0.2$ & $+0.0 \pm 0.2$ & 0.8389 \\
\hline Waist circumference $(\mathrm{cm})$ & $-2.1 \pm 0.6$ & $-2.0 \pm 0.7$ & 0.9115 \\
\hline Systolic BP (mmHg) & $-0 \pm 3$ & $-1 \pm 3$ & 0.8732 \\
\hline Diastolic BP (mmHg) & $+0 \pm 2$ & $-1 \pm 2$ & 0.6321 \\
\hline 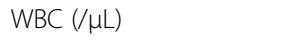 & $+570 \pm 270$ & $+320 \pm 300$ & 0.5661 \\
\hline $\mathrm{RBC}\left(\times 10^{6} / \mu \mathrm{L}\right)$ & $+0.16 \pm 0.04$ & $-0.01 \pm 0.05$ & $0.0134^{*}$ \\
\hline $\mathrm{Hb}(\mathrm{g} / \mathrm{dL})$ & $+0.8 \pm 0.2$ & $+0.3 \pm 0.2$ & 0.0548 \\
\hline $\mathrm{Ht}(\%)$ & $+0.9 \pm 0.5$ & $-0.8 \pm 0.5$ & $0.0251^{*}$ \\
\hline $\operatorname{PLT}\left(\times 10^{3} / \mu \mathrm{L}\right)$ & $+1 \pm+1$ & $+1 \pm 1$ & 0.5809 \\
\hline $\log$ TG (log mg/dL) & $+0.04 \pm 0.06$ & $-0.05 \pm 0.07$ & 0.3323 \\
\hline $\mathrm{HDL}-\mathrm{C}(\mathrm{mg} / \mathrm{dL})$ & $+2 \pm 2$ & $-1 \pm 2$ & 0.2586 \\
\hline $\mathrm{LDL}-\mathrm{C}(\mathrm{mg} / \mathrm{dL})$ & $+9 \pm 3$ & $+4 \pm 3$ & 0.2690 \\
\hline $\log$ FPG (log mg/dL) & $+0.01 \pm 0.01$ & $+0.05 \pm 0.01$ & $0.0297^{*}$ \\
\hline $\log F \mid R I(\log \mu \mid U / m L)$ & $+0.05 \pm 0.11$ & $+0.04 \pm 0.12$ & 0.9486 \\
\hline $\log \mathrm{HbA} 1 \mathrm{c}(\log \%)$ & $-0.0 \pm 0.0$ & $-0.0 \pm 0.0$ & 0.9945 \\
\hline $\log$ HOMA-IR & $+0.07 \pm 0.11$ & $+0.08 \pm 0.13$ & 0.9296 \\
\hline $\log$ HOMA-B & $+0.02 \pm 0.10$ & $-0.05 \pm 0.11$ & 0.6027 \\
\hline $\log |G|$ & $+0.25 \pm 0.11$ & $-0.13 \pm 0.12$ & $0.0319^{*}$ \\
\hline $\log$ DHEA-S (log $\mu \mathrm{g} / \mathrm{dL})$ & $+0.08 \pm 0.04$ & $+0.20 \pm 0.04$ & $0.0483^{*}$ \\
\hline male & $+0.06 \pm 0.06$ & $+0.22 \pm 0.07$ & 0.1517 \\
\hline female & $+0.11 \pm 0.04$ & $+0.17 \pm 0.05$ & 0.4672 \\
\hline $\log T(\log n g / m L)$ & $+0.12 \pm 0.04$ & $-0.02 \pm 0.05$ & 0.0416 \\
\hline male & $+0.06 \pm 0.03$ & $-0.06 \pm 0.03$ & 0.0503 \\
\hline female & $+0.24 \pm 0.10$ & $-0.02 \pm 0.11$ & 0.1369 \\
\hline $\log$ E2 (log pg/mL) & $-0.01 \pm 0.04$ & $+0.04 \pm 0.04$ & 0.3955 \\
\hline male & $+0.02 \pm 0.06$ & $+0.07 \pm 0.06$ & 0.6303 \\
\hline female & $-0.06 \pm 0.06$ & $+0.03 \pm 0.07$ & 0.3756 \\
\hline $\log$ T/DHEAS & $+0.05 \pm 0.05$ & $-0.23 \pm 0.59$ & $0.0015^{*}$ \\
\hline male & $-0.01 \pm 0.06$ & $-0.27 \pm 0.06$ & $0.0153^{*}$ \\
\hline female & $+0.12 \pm 0.10$ & $-0.19 \pm 0.12$ & 0.0848 \\
\hline $\log E 2 / T$ & $-0.11 \pm 0.06$ & $+0.04 \pm 0.06$ & 0.1034 \\
\hline male & $+0.01 \pm 0.07$ & $+0.09 \pm 0.07$ & 0.4745 \\
\hline female & $-0.28 \pm 0.11$ & $+0.02 \pm 0.13$ & 0.1353 \\
\hline \multicolumn{4}{|l|}{ SF-36 subscale scores } \\
\hline PF & $+2 \pm 1$ & $-1 \pm 1$ & 0.1384 \\
\hline RP & $-6 \pm 3$ & $-4 \pm 3$ & 0.6050 \\
\hline BP & $+0 \pm 4$ & $-4 \pm 4$ & 0.4701 \\
\hline $\mathrm{GH}$ & $+16 \pm 12$ & $-6 \pm 14$ & 0.2856 \\
\hline$V T$ & $+7 \pm 3$ & $-1 \pm 3$ & 0.0924 \\
\hline SF & $-1 \pm 4$ & $-6 \pm 4$ & 0.4395 \\
\hline RE & $-3 \pm 3$ & $-4 \pm 3$ & 0.8287 \\
\hline $\mathrm{MH}$ & $+4 \pm 3$ & $-7 \pm 3$ & $0.0276^{*}$ \\
\hline
\end{tabular}

Abbreviations were denoted in the text. ${ }^{*} P<0.05$. the reasons why we could not obtain any effect on serum lipids is smaller doses of RJ in our study. The subjects in their RJ group had taken $6 \mathrm{~g}$ of RJ a day for 4 weeks, in contrast to $3000 \mathrm{mg}$ a day for 6 months in our RJ trial. Another possibility is that the lipid lowering effect of RJ may be transient and not last for six months.

We could not find any papers which described the effect of RJ on anemia. Most of our participants did not have anemia and the increase in RBC and Ht was modest. There was no significant change in mean corpuscular volume and mean corpuscular hemoglobin between before and after intervention (data not shown), suggesting that RJ did not promote iron metabolism or hemoglobin synthesis but stimulated erythropoiesis or prolonged the lifespan of erythrocytes. The most probable reason is acceleration of erythropoiesis by testosterone which increased in serum in the present study. Testosterone is an anabolic steroid and has been used to treat several types of anemia.

E2 is a primary estrogen in humans and is converted from $\mathrm{T}$ by aromatase located in the ovary or adipose tissues. Most of our female participants were over the age of 50 and after menopause, resulting in lower serum E2 levels in women than those in men. DHEA-S is the most abundant androgen in human beings and is synthesized in the adrenal. It is then converted to $\mathrm{T}$ through androstenedione by $3 \beta$-hydroxysteroid dehydrogenase type 2 $(3 \beta$-HSD2) and $17 \beta$-hydroxysteroid dehydrogenase type 3 (17ß-HSD3) located in the adrenal and testis [25]. In the present trial, less increase in DHEA-S and more increase in $\mathrm{T}$ in the RJ group than in the control one was observed, suggesting that RJ may have induced the conversion of DHEA-S to T by stimulating $3 \beta-\mathrm{HSD} 2$ and/or $17 \beta$-HSD3 as shown in Figure 2. Serum T/DHEA-S and $\mathrm{E} 2 / \mathrm{T}$ ratios are considered to be designated activities of $3 \beta$-HSD2 and/or 17 $\beta$-HSD3 and aromatase, respectively. The changes of log T/DHEA-S ratio were significantly higher only in the men, suggesting that RJ may induce $3 \beta$-HSD2 and/or 17 $\beta$-HSD3 activity in the testis. It is possible that RJ also could promote those enzyme activities in the ovary if the women had normal menstrual cycles. In contrast, the changes of log E2 and log E2/T ratios were not different, indicating that RJ may have no action on aromatase in human beings. The enhanced $3 \beta$-HSD2 and/or $17 \beta$-HSD3 activity may result from high antioxidant enzyme activities of RJ [26].

RJ did not improve HOMA-IR or HbA1c but FPG and IGI were in the present study, suggesting that RJ stimulated insulin secretion. The improvement of glucose tolerance may have been brought about by a rise of $\mathrm{T}$. $\mathrm{T}$ replacement restores insulin action, increases islet insulin content, and enhances insulin secretion in rats [27]. In contrast, treatment with $\mathrm{T}$ in elderly men does not improve carbohydrate tolerance or alter 
insulin secretion, insulin action, or glucose effectiveness [28].

No significant differences in atherosclerotic and bone metabolic variables were observed (data not shown). The six month intervention may have been too short to elucidate the effect on baPWV and BMD. However, no effects on other variables, homocystein, hmw-adiponectin, NTx and ucOC, may indicate that RJ has no beneficial potency on atherosclerosis or bone metabolism.

Improvement of $\mathrm{MH}$ of SF-36 subscales was observed. The changes of $\mathrm{MH}$ as well as PF were also significant in men, suggesting that the beneficial effects on quality of life in men may be a secondary action of $\mathrm{T}$ elevation. In late onset hypogonadism patients, testosterone replacement therapy resulted in the improvement of six of eight domains including $\mathrm{MH}$ and PF in SF-36 [29]. In a stress-inducible depression-like mouse model, 10hydroxy-trans-2-decenoic acid, an unsaturated fatty acid unique to RJ, protected against depression and anxiety [30].

In the present study, we did not observe any serious adverse effects of RJ. In the literature, several cases of hemorrhagic colitis [31], asthma [32] and anaphylaxis [33] by ingestion of RJ have been reported. RJ should be considered as a causative allergen. Increased consumption of RJ in health food supplements may increase incidence of RJ-related allergic reactions [33].

\section{Limitations}

This study had several limitations. First, the sample size was minimal and may have been too small for some measures to reach statistical significance, especially in the case of analysis by gender. Second, we do not know the most effective dose of RJ for a human being. Larger or smaller daily amounts of RJ may have been necessary to produce some important effects.

\section{Conclusion}

In conclusion, six-month ingestion of RJ in humans improved erythropoiesis, glucose tolerance and mental health. These may be due to secondary effects of $\mathrm{T}$ with acceleration of conversion from DHEA-S to $\mathrm{T}$ by activation of $3 \beta$-HSD2 and/or 17 $\beta$-HSD3 through anti-oxidant enzyme potential of RJ. A RCT with larger number of subjects will be necessary to further verify the effects of $\mathrm{RJ}$ in more detail.

\section{Abbreviations}

RJ: Royal jelly; DHEA-S: Dehydroepiandrosterone sulfate; T: Testosterone; TC: Total cholesterol; LDL: Low density lipoprotein; E2: Estradiol; HbA1c: Hemoglobin A1c; BMI: Body mass index; baPWV: Brachial-ankle pulse wave velocity; BMD: Bone mineral density; OGTT: $75 \mathrm{~g}$ oral glucose tolerance test; MHPG: 3-methoxy-4-hydroxy-phenylglycol; hsCRP: High sensitive C-reactive protein; hmw: High-molecular-weight; ucOC: Undercarboxylated osteocalcin; NTx: N-telopeptides of type I collagen; 8-OHdG: 8-hydroxy-2'deoxyguanosine; HOMA-IR: Homeostatic model assessment-insulin resistance index; FIRI: Fasting immunoreactive insulin; FPG: Fasting plasma glucose; HOMA-B: HOMA of $\beta$-cell function index; IGI: Insulinogenic index; eGFR: Estimated glomerular filtration rate; HDL-C: High density lipoprotein cholesterol; CRE: Creatinine; SF-36: Medical Outcomes Study 36-Item Short-Form Health Survey; PF: Physical functioning; RP: Role limitations due to physical problems; BP: Bodily pain; GH: General health perception; VT: Vitality; SF: Social functioning; RE: Role of limitation due to emotional problems; MH: Mental health; RBC: Red blood cell counts; Ht: Hematocrit; RIA: Radioimmunoassay; CLEIA: Chemiluminescent enzyme immunoassay; ELISA: Enzyme-linked immunosorbent assay; ANCOVA: Analysis of covariance;

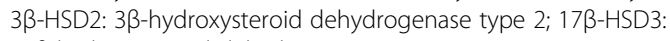

17ß-hydroxysteroid dehydrogenase type 3 .

\section{Competing interests}

The authors declare no conflict of interest.

\section{Authors' contributions}

The authors' responsibilities were as follows: HM, KK and TIs designed and conducted research; HM, KK, TIK, IM, KF, HO and YU participated in the checkups and collected data; HM and YU performed the statistical analysis; HM and Tls wrote the paper; HM had primary responsibility for final content. All authors read and approved the final manuscript. The study sponsors had no role in the study design; collection, analysis, or interpretation of the data; writing of the paper; or decision to submit the manuscript for publication.

\section{Acknowledgements}

We are grateful to our volunteers whose availability made this work possible and to Mr. Yukio Narita, Kenji Ichihara and Satoshi Mishima, Nagaragawa Research Center, API Co., Ltd. for preparing RJ and its placebo and technical assistance. We also appreciate ZEN-NOH (Tokyo, Japan) providing us a place for the checkups.

\section{Funding}

This trial was supported in part by a Grant-in-Aid for Scientific Research (research project number 16300220 and 22500626) from the Japan Society for the Promotion of Science, and collaborative research grants from API Co., Ltd. and ISET Co.

Received: 20 March 2012 Accepted: 18 September 2012 Published: 21 September 2012

\section{References}

1. Patel NG, Haydak MH, Gochnauer TA: Electrophoretic components of the proteins in honeybee larval food. Nature 1960, 186:633-634.

2. Takenaka T: Chemical composition of royal jelly. Honeybee Sci 1982, 3:69-74. 
3. Townsend GF, Morgan JF, Tolnai S, Hazlett B, Morton HJ, Shuel RW: Studies on the in vitro antitumor activity of fatty acids. I. 10-Hydroxy-2-decenoic acid from royal jelly. Cancer Res 1960, 20:503-510.

4. Nakajima Y, Tsuruma K, Shimazawa M, Mishima S, Hara H: Comparison of bee products based on assays of antioxidant capacities. BMC Complement Altern Med 2009, 9:4.

5. Kohno K, Okamoto I, Sano O, Arai N, Iwaki K, Ikeda M, Kurimoto M: Royal jelly inhibits the production of proinflammatory cytokines by activated macrophages. Biosci Biotechnol Biochem 2004, 68(1):138-145.

6. Tseng JM, Huang JR, Huang HC, Tzen JT, Chou WM, Peng CC: Facilitative production of an antimicrobial peptide royalisin and its antibody via an artificial oil-body system. Biotechnol Prog 2011, 27(1):153-161.

7. Okamoto I, Taniguchi Y, Kunikata T, Kohno K, Iwaki K, Ikeda M, Kurimoto M: Major royal jelly protein 3 modulates immune responses in vitro and in vivo. Life Sci 2003, 73(16):2029-2045.

8. Park HM, Cho MH, Cho Y, Kim SY: Royal jelly increases collagen production in rat skin after ovariectomy. J Med Food 2012, 15(6):568-575.

9. Tokunaga KH, Yoshida C, Suzuki KM, Maruyama H, Futamura Y, Araki Y, Mishima S: Antihypertensive effect of peptides from royal jelly in spontaneously hypertensive rats. Biol Pharm Bull 2004, 27(2):189-192.

10. Guo H, Saiga A, Sato M, Miyazawa I, Shibata M, Takahata Y, Morimatsu F. Royal jelly supplementation improves lipoprotein metabolism in humans. J Nutr Sci Vitaminol (Tokyo) 2007, 53(4):345-348.

11. Yakoot M, Salem A, Omar AM: Effectiveness of a herbal formula in women with menopausal syndrome. Forsch Komplementmed 2011, 18(5):264-268.

12. Kohguchi M, Inoue S, Ushio S, Iwaki K, Ikeda M, Kurimoto M: Effect of royal jelly diet on the testicular function of hamsters. Food Sci Technol Res 2004, 10(4):420-423.

13. Elnagar SA: Royal jelly counteracts bucks" "summer infertility". Anim Reprod Sci 2010, 121(1-2):174-180.

14. Enomoto M, Adachi H, Fukami A, Furuki K, Satoh A, Otsuka M, Kumagae S, Nanjo $Y$, Shigetoh $Y$, Imaizumi T: Serum dehydroepiandrosterone sulfate levels predict longevity in men: $27-y e a r$ follow-up study in a community-based cohort (Tanushimaru study). J Am Geriatr Soc 2008, 56(6):994-998

15. Matsumoto M, Ishizuka T, Kajita K, Sugiyama C, Morita $H$, Uno Y, Ikeda T, Mori I, Matsubara K, Takeda N, et al: Dehydroepiandrosterone-sulfate concentration in men from a Japanese longevity district. Geriatr Gerontol Int 2007, 7(4):352-356.

16. Talaei A, Amini M, Siavash M, Zare M: The effect of dehydroepiandrosterone on insulin resistance in patients with impaired glucose tolerance. Hormones (Athens) 2010, 9(4):326-331.

17. Ishizuka T, Kajita K, Miura A, Ishizawa M, Kanoh Y, Itaya S, Kimura M, Muto N, Mune T, Morita $\mathrm{H}$, et al: DHEA improves glucose uptake via activations of protein kinase C and phosphatidylinositol 3-kinase. Am J Physiol 1999, 276(1 Pt 1):E196-E204.

18. Ishizuka T, Miura A, Kajita K, Matsumoto M, Sugiyama C, Matsubara K, Ikeda T, Mori I, Morita H, Uno Y, et al: Effect of dehydroepiandrosterone on insulin sensitivity in Otsuka Long-Evans Tokushima-fatty rats. Acta Diabetol 2007, 44(4):219-226.

19. Roth GS, Lane MA, Ingram DK, Mattison JA, Elahi D, Tobin JD, Muller D, Metter EJ: Biomarkers of caloric restriction may predict longevity in humans. Science 2002, 297(5582):811.

20. Kalish GM, Barrett-Connor E, Laughlin GA, Gulanski Bl: Association of endogenous sex hormones and insulin resistance among postmenopausal women: results from the Postmenopausal Estrogen/ Progestin Intervention Trial. J Clin Endocrinol Metab 2003, 88(4):1646-1652.

21. Fukuhara S, Bito S, Green J, Hsiao A, Kurokawa K: Translation, adaptation, and validation of the SF-36 Health Survey for use in Japan. J Clin Epidemiol 1998, 51(11):1037-1044.

22. Fukuhara S, Ware JE Jr, Kosinski M, Wada S, Gandek B: Psychometric and clinical tests of validity of the Japanese SF-36 Health Survey. J Clin Epidemiol 1998, 51(11):1045-1053.

23. Kamakura M: Royalactin induces queen differentiation in honeybees. Nature 2011, 473(7348):478-483.

24. Abdelhafiz AT, Muhamad JA: Midcycle pericoital intravaginal bee honey and royal jelly for male factor infertility. Int J Gynaecol Obstet 2008, 101(2):146-149.

25. Zhao B, Chu Y, Hardy DO, Li XK, Ge RS: Inhibition of 3beta- and 17betahydroxysteroid dehydrogenase activities in rat Leydig cells by perfluorooctane acid. J Steroid Biochem Mol Biol 2010, 118(1-2):13-17.
26. Cemek M, Yilmaz F, Buyukokuroglu ME, Buyukben A, Aymelek F, Ayaz A: Serum and liver tissue bio-element levels, and antioxidant enzyme activities in carbon tetrachloride-induced hepatotoxicity: protective effects of royal jelly. J Med Food 2012, 15(8):747-752.

27. Morimoto S, Fernandez-Mejia C, Romero-Navarro G, Morales-Peza N, DiazSanchez V: Testosterone effect on insulin content, messenger ribonucleic acid levels, promoter activity, and secretion in the rat. Endocrinology 2001, 142(4):1442-1447.

28. Basu R, Dalla Man C, Campioni M, Basu A, Nair KS, Jensen MD, Khosla S, Klee G, Toffolo G, Cobelli $C$, et al: Effect of 2 years of testosterone replacement on insulin secretion, insulin action, glucose effectiveness, hepatic insulin clearance, and postprandial glucose turnover in elderly men. Diabetes Care 2007, 30(8):1972-1978.

29. Amano T, Imao T, Takemae K, Iwamoto T, Nakanome M: Testosterone replacement therapy by testosterone ointment relieves lower urinary tract symptoms in late onset hypogonadism patients. Aging Male 2010, 13(4):242-246

30. Ito S, Nitta Y, Fukumitsu H, Soumiya H, Ikeno K, Nakamura T, Furukawa S: Antidepressant-like activity of 10-hydroxy-trans-2-decenoic acid, a unique unsaturated fatty acid of royal jelly, in stress-inducible depression-like mouse model. Evid Based Complement Alternat Med 2012, 2012:139-140.

31. Yonei $Y$, Shibagaki $K$, Tsukada N, Nagasu N, Inagaki $Y$, Miyamoto K, Suzuki O, Kiryu Y: Case report: haemorrhagic colitis associated with royal jelly intake. J Gastroenterol Hepatol 1997, 12(7):495-499.

32. Thien FC, Leung R, Baldo BA, Weiner JA, Plomley R, Czarny D: Asthma and anaphylaxis induced by royal jelly. Clin Exp Allergy 1996, 26(2):216-222.

33. Katayama M, Aoki M, Kawana S: Case of anaphylaxis caused by ingestion of royal jelly. J Dermatol 2008, 35(4):222-224.

\section{doi:10.1186/1475-2891-11-77}

Cite this article as: Morita et al:: Effect of royal jelly ingestion for six months on healthy volunteers. Nutrition Journal 2012 11:77.

\section{Submit your next manuscript to BioMed Central and take full advantage of:}

- Convenient online submission

- Thorough peer review

- No space constraints or color figure charges

- Immediate publication on acceptance

- Inclusion in PubMed, CAS, Scopus and Google Scholar

- Research which is freely available for redistribution

Submit your manuscript at www.biomedcentral.com/submit
C) Biomed Central 